\section{Pterygium in an aged Mongolian population: a population-based study in China}

J Lu ${ }^{1,2}$, Z Wang ${ }^{1}$, P Lu ${ }^{3}$, X Chen ${ }^{3}$, W Zhang ${ }^{2}$, K Shi $^{2}$, $Y K^{\prime} a n{ }^{4}, L K^{4}$ and $R$ Chen $^{5}$

\begin{abstract}
Aims To determine the prevalence and identify associated risk factors for pterygium in an elderly Mongolian population at high altitude in Henan County, China.

Methods A population-based survey was conducted from June 2006 to September 2006. A stratified, clustered, random sampling procedure was used to select 2486 Mongolian people aged 40 years and older. Pterygium was diagnosed and graded clinically as grade 1 (transparent), 2 (intermediate), and 3 (opaque). Risk factors associated with pterygium were evaluated with logistic regression models.
\end{abstract} Results From 2486 eligible subjects, 2112 (84.9\%) were examined. There were 378 people with either unilateral $(n=228)$ or bilateral $(n=150)$ pterygia, equivalent to an overall prevalence of $17.9 \%$ (95\% confidence interval (CI) 16.3, 19.5). The prevalence increased with older age $\left(\chi^{2}\right.$-test of trend $\left.P<0.001\right)$. Visual acuity decreased with higher group of pterygium $\left(\chi^{2}=97.759, P<0.0001\right)$. Pterygium was independently associated with Schirmer's test ( $\leqslant 5 \mathrm{~mm}$ ) (odds ratio (OR) 2.4; 95\% CI, 1.9, 3.1), tear breakup time ( $\leqslant 10 \mathrm{~s})$ (OR 2.3; 95\% CI, 1.8, 2.9), lower education level ( $<3$ years) (OR 2.1; 95\% CI, 1.4, 3.2), increasing age (OR 2.0; 95\% CI, 1.4, 2.8) for persons 70-79, compared with 40-49, and other risk factors.

Conclusions The prevalence of pterygium in an older Mongolian population at high altitude is high, primarily because of ocular sun exposure and the other effects of the unique plateau climate, and representing an important health problem. People should be strongly encouraged to wear a wide-brimmed hat and/or sunglasses whenever they are outside.

Eye (2009) 23, 421-427; doi:10.1038/sj.eye.6703005; published online 19 October 2007

\section{Introduction}

Pterygium is a common ophthalmic disease of unknown cause and pathogenesis, ${ }^{1}$ and it was called as an ophthalmic enigma. ${ }^{2}$ However, many regard it to be a consequence of ultraviolet-induced damage with subsequent elastoid degeneration of the subepithelial connective tissue, ${ }^{3-5}$ and it is strongly related to ocular sun exposure. ${ }^{6-9}$ The prevalence rates of pterygium obtained from a number of populations range from $1.2 \%$ in urban Caucasians $^{9}$ to $31.01 \%$ in rural Chinese in southern China. ${ }^{10}$

To the best of our knowledge, very few data are available on the prevalence of pterygium in Mongolian people at high altitude. In light of the hypothesis that pterygium is related to ocular sun exposure, a population-based prevalence survey in Mongolian people who live at high altitude was conducted from September 2006 to December 2006. The purpose of this survey was to understand the prevalence of pterygium in an elderly native Mongolian population at high altitude in Henan County, and identify associated risk factors for pterygium.

\section{Materials and methods}

This investigation was part of a populationbased study of ocular disorders among Mongolian people aged 40 years and older living in Henan County, China, the Henan Eye Survey (HES). Henan County (East longitude of $100^{\circ} 53^{\prime}-102^{\circ} 15^{\prime}$ and north latitude of $34^{\circ} 04^{\prime}-$ $34^{\circ} 55^{\prime}$ ) is located in the eastern part of the Qinghai-Tibetan Plateau, China. The average altitude of Henan County is $3450 \mathrm{~m}$, with a land area of $6997 \mathrm{~km}^{2}$. It has 6 townships and 49 villages. The country has a constant high altitude climate with a yearly mean temperature
${ }^{1}$ Institute of Developmental Biology, School of Life Sciences, Lanzhou University, Lanzhou, China

${ }^{2}$ Department of Ophthalmology, Second Hospital, Lanzhou University, Lanzhou, China

${ }^{3}$ Department of Ophthalmology, West China Hospital, Sichuan University, Chengdu, China

${ }^{4}$ Department of Ophthalmology, The People's Hospital of Huangnan Tibetan Autonomous Prefecture, Tongren, China

${ }^{5}$ Department of Ophthalmology, The People's Hospital of Henan County, Henan, China

Correspondence: P Lu, Department of Ophthalmology, West China Hospital, Sichuan University, Guoxue Xiang 37\#, Chengdu, Sichuan Province 610041, China

Tel: + 8628 85423235;

Fax: + 862885422539

E-mails: qinghaidavid@ yahoo.com.cn or qinghailaoq@ hotmail.com

Received: 28 March 2007 Accepted in revised form: 16 September 2007 Published online: 19 October 2007 
of $-3^{\circ} \mathrm{C}$, daily mean total global radiation of $625 \mathrm{kj} / \mathrm{cm}^{2}$, and $2650 \mathrm{~h}$ of sunshine per year (2005, Meteorological Service, Bureau of Environment, Qinghai, China). The socioeconomic status is at the lower end of the norm in China. Henan County was chosen as the study community after considering population stability, metropolitan areas, sea level, and local support into consideration.

\section{Selection of subjects}

According to the 2004 population census, the total population of Henan County was 32616, with native Mongolians being 30422 (93.3\% of the total). The number of native Mongolians aged 40 and older were 6449 (21.2\%) of all native Mongolians. Residents 40 years of age and older were identified by the household registration system.

The stratified, clustered, random sampling method was used for sampling drawing. For determining the sample size, the prevalence of blindness for adults 40 years and above was estimated to be $5 \%$. We assumed a design effect of 1.5 (for cluster sampling), a confidence interval (CI) of 95\%, an allowable error of $25 \%$, and a response rate of $80 \%$. These assumptions led to a sample size of 2426 . We used the villages as the primary sampling units (PSUs) ${ }^{11}$ for the entire county. The number of native Mongolians in each PSU was within the range of 450-600. There were 47 PSUs actually involved in this survey, in 28596 (94.0\%) of the county's total Mongolian population. The random digits table was used to draw 19 units from those PSUs to fit the needs of the sample. Two thousand four hundred and eighty-nine native Mongolians 40 years and older were eligible. All participants were native Mongolians who were born and grown up in the selected area.

\section{The pre-survey stage and pilot study}

Contacts were made from April 2006 to May 2006 with the local government and correlated constitutions to negotiate the detailed affairs of the survey, and informed the individuals who were in the selected PSUs. Before the formal survey began, 1 week's training and a pre-survey were conducted (the first 1 week of June 2006). The pilot study was conducted outside the study area and these results were excluded from this study. A total of 216 individuals from another county near by Henan County were examined. These examinations revealed weaknesses in the examination procedures and in the organization of the processes and procedures. These weaknesses were successfully addressed before implementation of the main study.

\section{Data collection}

The fieldwork of data collection was started and conducted from June 2006 to September 2006. A team of five ophthalmologists, administrative personnel from the villages, and the medical workers of the township clinics (they also acted as translators) carried out the data collection. The team was equipped with two vehicles, Snellen's E charts, two slit-lamp microscopes (Model YZ-5E, Crane, China), a stereo-ophthalmoscope (Keeler, UK) with a Volk $20 \mathrm{D}$ lens. The team also was equipped with power generators for locations without electricity.

At locally established test sites (at local clinics), the participants underwent the examinations, including a personal interview, visual acuity, signs of dry eyes, slit-lamp assessment of anterior segment and lens, and fundus evaluation. Ophthalmologists conducted the eye examinations according to a standardized protocol.

A standardized interview was conducted on all participants and a structured questionnaire was used to obtain information based on demographic data (name, age, gender, locality, economic status, and education) and lifestyle (smoking, alcohol intake, wears a hat or sunglasses). Participants' self-reported demographic data were assessed. Age was defined as the current age at the time of survey. Education level was ascertained by the question, 'How many years have you been in school?' We classified these answers into four categories: never, less than 3 years, 3- 6 years, and more than 6 years. Family economic status was measured according to the number of yaks in the family, since yaks are one of the most important domestic animals for this group of Mongolian population. Three categories were classified: low (less than 10 yaks), middle (10-50 yaks), and high (more than 50 yaks). Symptoms of dry eye were assessed using a six-item validated questionnaire, ${ }^{12}$ presence of one or more of the six dry eye symptoms often or all the time was analyzed. People were asked to state when outdoors if they wore a hat, sunglasses, or stone spectacles (seldom or often). The participants were also asked questions about their cigarette-smoking history (smoker and non-smoker). Alcohol intake was categorized as no habit of alcohol consumption and a habit of alcohol consumption.

As part of the standardized eye examination, a slit-lamp (Model YZ) was used to examine the anterior segment for evidence of pterygium. The diagnosis of pterygium was made clinically by a single examiner (PL). The Schirmer's test was performed $1 \mathrm{~min}$ after instillation of a drop of $0.5 \%$ proparacaine (Alcaine, Alcon-Couveur, Belgium), and any visible fluid in the inferior fornix or lid margin was gently dried with a cotton swab. A precalibrated filter strip (Tianjin Jingming New Technological Development Co. Ltd, China) was then placed temporally in each lower fornix and left in place 
for $5 \mathrm{~min}$. The patient was encouraged to close his/her eyes but allowed to blink normally. After $5 \mathrm{~min}$, the strip was removed, and the amount of wetting was recorded. The tear-film breakup time test was repeated three times for each eye, and the average time was recorded.

\section{Diagnostic criteria}

Pterygium was diagnosed if a characteristic raised fleshy growth crossing the corneoscleral limbus and encroaching on the clear cornea was present ${ }^{13}$ or if pterygium surgery had been performed. A system of grading pterygia according to their morphology has been developed for use in pterygium studies. ${ }^{14,15}$ Grade T1 (transparent) includes a pterygium in which episcleral vessels underlying the body of the pterygium are clearly distinguished and unobscured and grade T3 (opaque) a thick, fleshy pterygium in which episcleral vessels underlying the body of the pterygium are totally obscured. All other pterygia that do not fall into these two categories fall into grade T2 (intermediate). If a patient had bilateral pterygia, the grade was classified according to the higher grade in either eye. Age-related cataracts were assessed by use of the Lens Opacity Classification System III, 16,17 by a senior ophthalmologist (XC). Subjects with congenital or traumatic cataracts in one or both eyes were excluded from this analysis.

\section{Data processing and statistic analysis}

Fixed people for fixed items filled the results of the survey in the forms. Questions were solved by discussion with the entire team. SPSS (Statistical Package for Social Sciences Inc., Chicago, IL, USA) version 12.0 was used for statistical analysis and $P<0.05$ was considered statistically significant. The prevalence rates and 95\% CI of pterygium for subjects were calculated. The association between gender, age, educational level, lifestyle, and other variables and the risk of pterygia was estimated by the odds ratio (OR) and its $95 \%$ CI. The significance of visual acuity on patients with different types of pterygium was evaluated by $\chi^{2}$-test. The independent effect of risk factors was evaluated using logistic regression models.

This survey was approved by the Ethics Committee of the Qinghai Provincial Health Bureau and was carried out in accordance with the tenets of the Declaration of Helsinki Principal (revised in 2000). All the participants gave verbal consent and all the examinations and treatment were free of charge.

\section{Results}

Among the 2486 native Mongolians 40 years and older who were eligible to participate in this study, 2112 underwent the survey. The overall response rate was $84.9 \%$, including 1125 male cases (53.3\%). Table 1 shows the age, gender, the level of education, and economic situation of the family. The average age for the individuals who underwent the survey was $54.85 \pm 11.72$.

There were 378 people with either unilateral $(n=228)$ or bilateral ( $n=150)$ pterygia, equivalent to an overall prevalence of $17.9 \%$ (95\% CI, 16.3, 19.5) in the Mongolian population aged 40 and above (Table 2). None of the participants had undergone the pterygium surgery before. The age-adjusted prevalence rate was similar, $17.8 \%$ (95\% CI, 17.8, 17.9). The prevalence increased with age $\left(\chi^{2}\right.$-test of trend $\left.P<0.001\right)$.

Of the 378 persons with pterygium, 154 were classified as having grade $\mathrm{T} 1$ pterygium, 174 had grade $\mathrm{T} 2$, and the remaining 50 had grade T3 (Table 3). There were 150 persons with bilateral pterygia, 39.7\% (150/378) of the total. Table 4 shows visual acuity on patients with different types of pterygium.

Pterygium was independently associated with Schirmer's test ( $\leqslant 5 \mathrm{~mm}$ ) (OR 2.4; 95\% CI, 1.9, 3.1), tear breakup time ( $\leqslant 10 \mathrm{~s})(\mathrm{OR}, 2.3 ; 95 \% \mathrm{CI}, 1.8,2.9)$, lower education level ( $<3$ years) (OR, 2.1; 95\% CI, 1.4, 3.2), increasing age (OR, 2.0; 95\% CI, 1.4, 2.8) for persons 70-79, compared with 40-49, and other risk factors (Table 5).

\section{Discussions}

After the study of relevant materials from around the world in recent decades, we found the epidemiological survey of eye diseases for native dwellers at the high altitude was limited. In 1999-2000, a cross-sectional prevalence study of blindness in the Tibet Autonomous Region was conducted, but it was mainly focused on eye diseases resulting in blindness. The prevalence of pterygium was not included. ${ }^{18}$ To the best of our knowledge, this was the first population-based study to examine the prevalence and risk factors of pterygium in a Mongolian population in a region of high altitude. We found a high prevalence of pterygium in this Tibetan population: the overall prevalence of pterygium was $17.9 \%$ (95\% CI, 16.3, 19.5).

Previously reported prevalence of pterygia varies widely with geography, race, age, and gender. The earliest estimates were from a survey in New South Wales, Australia, which reported a $9.6 \%$ prevalence in participants aged 10 years and older. ${ }^{19}$ In China, a $7.86 \%$ prevalence in 7990 participants aged $12-88$ years has been reported. ${ }^{20}$

Studies that were based on adult populations confirm the higher prevalence of pterygium with increasing age. Prevalence in the Australian state of Victoria, where $2.83 \%$ of 5147 participants older than 40 years had pterygium, tended to increase with age in this 
population, with $6.4 \%$ of those aged $80-89$ years found to have pterygium. ${ }^{9}$ The Tanjong Pagar survey was $6.9 \%$ (95\% CI, 5.2, 8.8) in a sample of 1717 Chinese aged 40 and older. ${ }^{15}$ In the Blue Mountain Eye Study, the prevalence was $7.3 \%$ for participants aged 49 years or older. ${ }^{21}$ The prevalence of pterygium among 477 residents on a tropical island in Indonesia, however, was high, at $17.0 \%,{ }^{22}$ and the black population of the Barbados Eye Study was even higher, $23.4 \%$ of 2617 participants were aged 40-84 years. ${ }^{23}$ The highest prevalence of pterygium, to our knowledge, was in subjects aged 50 years or above in a rural area of southern China, 33.01\%. ${ }^{10}$ In HES, we found the prevalence of pterygium was 13.5 (95\% CI, $11.2,15.9)$ in participants aged $40-49$, but $27.5 \%(95 \% \mathrm{CI}$, $15.2,39.7)$ for those aged 80 and above.

Table 1 The distribution of gender, age, and the level of education of native Mongolian in Henan $(n=2112)$

\begin{tabular}{|c|c|c|c|c|c|c|}
\hline & \multicolumn{2}{|c|}{ Men } & \multicolumn{2}{|c|}{ Women } & \multicolumn{2}{|c|}{ Men and women } \\
\hline & $N$ & $\%$ & $N$ & $\%$ & $N$ & $\%$ \\
\hline \multicolumn{7}{|l|}{ Age (years) } \\
\hline $40-49$ & 454 & 21.5 & 367 & 17.4 & 821 & 38.9 \\
\hline $50-59$ & 314 & 14.9 & 285 & 13.5 & 599 & 28.4 \\
\hline $60-69$ & 204 & 9.7 & 173 & 8.2 & 377 & 17.9 \\
\hline $70-79$ & 131 & 6.2 & 133 & 6.3 & 264 & 12.5 \\
\hline 80 and above & 22 & 1.0 & 29 & 1.4 & 51 & 2.4 \\
\hline \multicolumn{7}{|c|}{ Education level (years) } \\
\hline 0 & 914 & 43.3 & 837 & 39.6 & 1751 & 82.9 \\
\hline$>3$ & 65 & 3.1 & 46 & 2.2 & 111 & 5.3 \\
\hline $3-6$ & 114 & 5.4 & 84 & 4.0 & 198 & 9.4 \\
\hline$>6$ & 32 & 1.5 & 20 & 0.9 & 52 & 2.5 \\
\hline \multicolumn{7}{|l|}{ Economic situation } \\
\hline Poor & 608 & 28.8 & 531 & 25.1 & 1139 & 53.9 \\
\hline Middle & 488 & 23.1 & 435 & 20.6 & 923 & 43.7 \\
\hline Rich & 29 & 1.4 & 21 & 1.0 & 50 & 2.4 \\
\hline Total & 1125 & 53.3 & 987 & 46.7 & 2112 & 100.00 \\
\hline
\end{tabular}

In medicine, high altitude is an area of altitude above $3000 \mathrm{~m}$, which has obvious biological effect on the human body. ${ }^{24}$ This survey was located on the Qinghai-Tibetan plateau where the average altitude was $3450 \mathrm{~m}$ and the individuals who underwent the survey were all native Mongolian living at high altitude. The unique environment of this high altitude area includes low air pressure, hypoxia, dry and cold weather, long periods or sunshine, strong solar infrared light and ultraviolet radiation, and some areas are covered by snow round the year. All of these factors have effects on the human body and the visual organ. ${ }^{25}$ We believe that this environment plays an important role for pterygium. However, we found no statistical significance of the prevalence for participants with pterygium between the altitudes of 3350-3600 $\mathrm{m}$ above sea level and altitudes higher than $4100 \mathrm{~m}$.

Native Mongolians are nomadic people and therefore the amount of time they stay outside during daylight hours is long, usually $6-9 \mathrm{~h}$ a day. Studies have shown that spending longer periods of time outdoors has led to an increased risk of pterygium, with cumulative exposure to ultraviolet radiation playing a significant role. ${ }^{7,6}$ A case-control study of 278 patients working in outside environments was shown to be 4-11 times more likely to have pterygium than those working indoors. ${ }^{27}$ These studies interpret the high prevalence of pterygium in HES.

For the Chesapeake Bay watermen, more than 8 years of education was found to be beneficial in protecting them from pterygium (OR $0.42 ; 95 \% \mathrm{CI}, 0.28,0.62) .{ }^{14} \mathrm{In}$ the Barbados Eye Study, logistic regression analyses indicated a positive association between pterygium and fewer years of education ( $\leqslant 12$ years) (OR $1.43 ; 95 \% \mathrm{CI}$, $1.01,2.03){ }^{23}$ The level of education was possibly as a result of a lower socioeconomic status in Mongolian people. The HES found that fewer years of education ( $<3$ years) had a positive effect on pterygium (OR 2.1;

Table 2 Prevalence of pterygium in native Mongolian in Henan by age and gender $(n=2112)$

\begin{tabular}{|c|c|c|c|c|c|c|c|c|c|c|}
\hline \multirow[t]{2}{*}{ Age (years) } & \multirow[t]{2}{*}{ Total $n$} & \multicolumn{3}{|c|}{ Men } & \multicolumn{3}{|c|}{ Women } & \multicolumn{3}{|c|}{ Men and women } \\
\hline & & $\mathrm{n}$ & $\%$ & $95 \% C I$ & $\mathrm{n}$ & $\%$ & $95 \% \mathrm{CI}$ & $\mathrm{n}$ & $\%$ & $95 \% C I$ \\
\hline $40-49$ & 821 & 56 & 6.8 & $(5.1,8.5)$ & 55 & 6.7 & $(5.0,8.4)$ & 111 & 13.5 & $(11.2,15.9)$ \\
\hline $50-59$ & 599 & 51 & 8.5 & $(6.3,10.7)$ & 56 & 9.4 & $(7.0,11.7)$ & 107 & 17.9 & $(14.8,20.9)$ \\
\hline $60-69$ & 377 & 45 & 11.9 & $(8.7,15.2)$ & 39 & 10.3 & $(7.3,13.4)$ & 84 & 22.3 & $(18.1,26.5)$ \\
\hline $70-79$ & 264 & 33 & 12.5 & $(8.5,16.5)$ & 29 & 11.0 & $(7.2,14.8)$ & 62 & 23.5 & $(18.4,28.6)$ \\
\hline 80 and above & 51 & 8 & 15.7 & $\begin{array}{l}(5.7,25.7) \\
0.001^{*}\end{array}$ & 6 & 11.8 & $\begin{array}{l}(2.9,20.6) \\
0.001^{*}\end{array}$ & 14 & 27.5 & $\begin{array}{l}(15.2,39.7) \\
0.001^{*}\end{array}$ \\
\hline $\begin{array}{l}\text { Total } \\
\text { Age adjusted rate }\end{array}$ & 2112 & 193 & $\begin{array}{l}9.1 \\
9.0\end{array}$ & $\begin{array}{c}(7.9,10.4) \\
(8.9,9.1)\end{array}$ & 185 & $\begin{array}{l}8.8 \\
8.7\end{array}$ & $\begin{array}{c}(7.6,10.0) \\
(8.7,8.8)\end{array}$ & 378 & $\begin{array}{l}17.9 \\
17.8\end{array}$ & $\begin{array}{l}(16.3,19.5) \\
(17.7,17.8)\end{array}$ \\
\hline
\end{tabular}

*Based on $\chi^{2}$-test of trend for age.

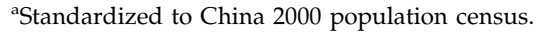


Table 3 Age and sex-specific prevalence rates of the different grades of pterygium in Henan $(n=2112)$

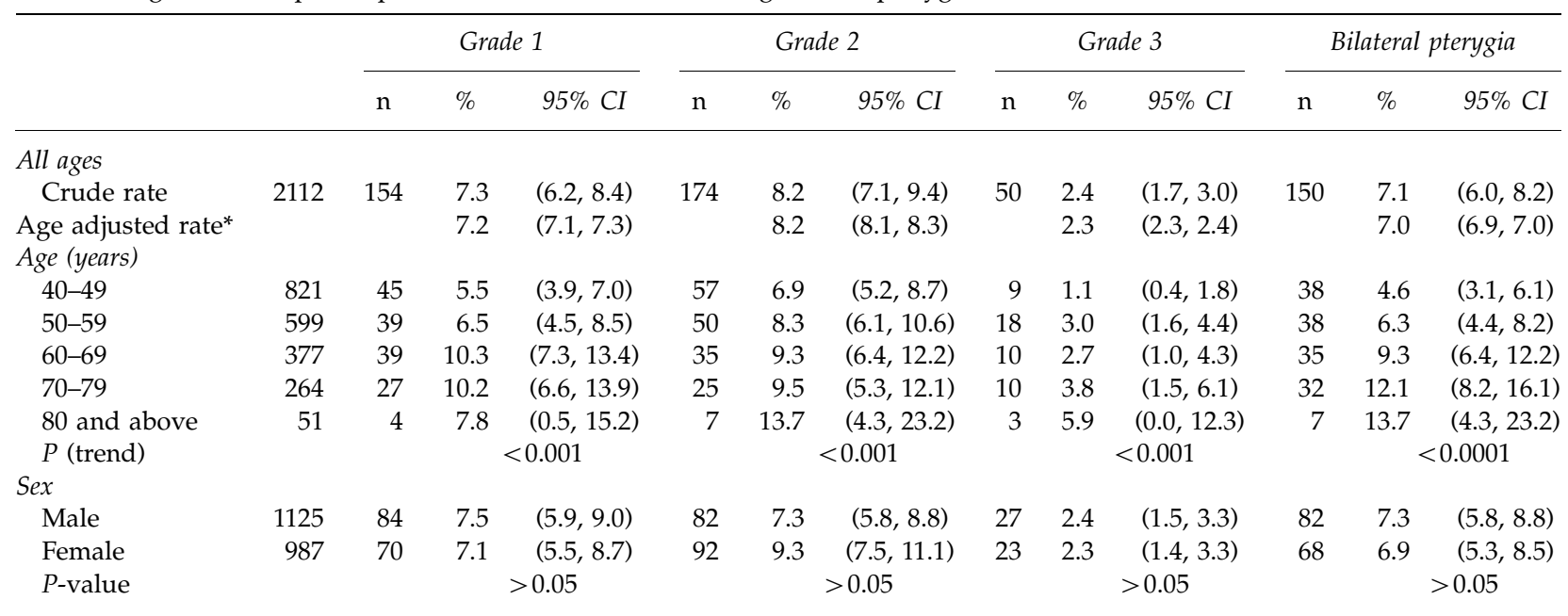

*Standardized to China 2000 population census.

Table 4 Visual acuity on patients with pterygium in Henna (eyes)

\begin{tabular}{lccccc}
\hline & $>6 / 6-6 / 12$ & $<6 / 12-6 / 20$ & $<6 / 20-3 / 60$ & $<3 / 60$ & Total \\
\hline Grade T1 & 134 & 27 & 10 & 0 & 171 \\
Grade T2 & 98 & 42 & 23 & 6 & 169 \\
Grade T3 & 8 & 9 & 7 & 12 & 36 \\
$P$-value** & $<0.0001$ & $<0.0001$ & $<0.0001$ & $<0.0001$ & \\
\hline
\end{tabular}

**Pearson $\chi^{2}=97.759, P<0.0001$.

${ }^{a}$ The participants with pterygium and other eye disorders that may affect visual acuity were excluded.

Table 5 Logistic regression results for associations of pterygium in Henan county $(n=2112)$

\begin{tabular}{lcc}
\hline Risk factors & $\begin{array}{c}\text { Odds ration } \\
(95 \% \text { CI })\end{array}$ & P-value \\
\hline Age, years (70-79 to 40-49) & $2.0(1.4,2.8)$ & $<0.001$ \\
Alcohol intake & $1.5(1.0,2.0)$ & $=0.028$ \\
Education ( $<3$ years) & $2.1(1.4,3.2)$ & 0.001 \\
Dry eye symptoms & $1.9(1.5,2.5)$ & $<0.001$ \\
Poor family situation & $1.3(1.0,1.6)$ & 0.044 \\
Schirmer test $(\leqslant 5 \mathrm{~mm})$ & $2.4(1.9,3.1)$ & $<0.001$ \\
Tear breakup time $(\leqslant 10 \mathrm{~s})$ & $2.3(1.8,2.9)$ & $<0.001$ \\
Seldom use of sunglasses/stone glasses & $1.5(1.2,1.9)$ & $<0.001$ \\
Seldom use of hat & $1.3(1.1,1.7)$ & 0.01 \\
Cataract & $1.5(1.1,1.9)$ & 0.006 \\
\hline
\end{tabular}

$95 \% \mathrm{CI}, 1.4,3.2)$ as did a low economic family status (OR 1.3; $95 \%$ CI, 1.0, 1.6).

Pterygium is known to affect refractive astigmatism, which can have a significant impact on vision. Vision may be reduced due to direct invasion of the visual axis or astigmatism induced by the pteygium. This study found that 18 eyes with pteygium had the visual acuity lower than 3/60 as a consequence of the lesion extending into the visual axis, and the operations were provided free of charge after the survey was completed. There is a statistical significance on visual acuity between the lower groups of pterygium to higher group of pterygium $\left(\chi^{2}=97.759, P<0.0001\right)$.

Reports on whether gender is related to pterygium have been differenced. The HES found no statistical significance in pterygia between men and women, which is consistent with some reports. ${ }^{9,21,28,29}$ From two studies conducted in China, women were at higher risk than men. ${ }^{10,20}$ The Blue Mountains Eye study ${ }^{21}$ and the Tanjong Pagar survey ${ }^{15}$ found that men were at higher risk than women; similar results were found by McCarty et $a l^{9}$ and Moran and Hollows. ${ }^{26}$

The survey found that the participants who seldom use sunglasses and/or wear a hat when they are outside had a positive association to pterygium (OR 1.5; 95\% CI, 1.2, 1.9 and OR 1.3; 95\% CI, 1.1, 1.7, respectively). This result was similar to the Barbados Eye Study ${ }^{23}$ and Rosenthal et al. ${ }^{30}$ We believe the protective mechanism is related to the ability of glasses and a hat to block ultraviolet- $B$ wavelengths of sunlight or to shield the eye from other harmful environmental exposures, since hazardous environmental factors play a very important role in pterygium formation.

The HES found a positive association between dry eye symptoms and pterygium (OR 1.9; 95\% CI, 1.5, 2.5). This finding is consistent with a population-based study in Indonesia (OR 1.8; 95\% CI, 1.4, 2.5). ${ }^{31}$ A case-control study has found an association between pterygium and a shortened tear breakup time and Schirmer's test. ${ }^{32}$ In HES, pterygium was also strongly associated with Schirmer's test ( $\leqslant 5 \mathrm{~mm})(\mathrm{OR} 2.4 ; 95 \% \mathrm{CI}, 1.9,3.1)$ and 
tear breakup time ( $\leqslant 10 \mathrm{~s})$ (OR 2.3; 95\% CI, 1.8, 2.9). We believe that pterygium may possibly be a distant surrogate for the environmental factors associated with dry eye, such as ultraviolet light quantities and a dusty polluted environment, which have been implicated in pterygium formation. ${ }^{33}$

Strengths of this survey include the population-based approach, minimizing the selection bias, and the examination of all subjects by a single ophthalmologist, minimizing inter-observer error. However, several limitations may affect the reliability of this survey. A total of $84.9 \%$ of the enumerated samples were examined. People living in inaccessible terrain and/or at the extremes of altitude were under-represented. These people may have a higher prevalence of pterygium. Participants' self-reported demographic data were assessed, which may have led to a subject bias, for example, the family economic situation.

In conclusion, pterygium is a significant public health problem in Henan County, primarily due to ocular sun exposure and the effects of the unique plateau climate, and representing an important health problem. The independent increase with age is consistent with previous findings. The other risk factors are dry eye sings and symptoms, seldom use of sunglasses or hat, alcohol intake, lower education level, and a lower economic status. People should be strongly encouraged to wear a wide-brimmed hat and/or sunglasses whenever they are outside.

\section{Acknowledgements}

We acknowledge local government officials and the workers at the seven township clinics for their painstaking and enthusiastic work. We thank the Henan People's Hospital for its organizational support and the Jian Hua Foundation Ltd for its funding support. We are also grateful to the Mongolian participants for their generous participation in the survey. This work as funded by Jian Hua Foundation Ltd.

The authors have no competing interests to declare.

\section{References}

1 Coroneo MT, Di Girolamo N, Wakefield D. The pathogenesis of pterygia. Curr Opin Ophthalmol 1999; 10: 282-288.

2 Coster D. Pterygium - an ophthalmic enigma. $\mathrm{Br}$ J Ophthalmol 1995; 79: 304-305.

3 Solomon A, Pires RT, Tseng SC. Amniotic membrane transplantation after extensive removal of primary and recurrent plerygia. Ophthalmology 2001; 108: 449-460.

4 Jaros PA, De Luise VP. Pingueculae and pterygia. Surv Ophthalmol 1988; 33: 41-49.
5 Coroneo MT. Pterygium as an early indicator of ultraviolet insolation: a hypothesis. Br J Ophthalmol 1993; 77: 734-739.

6 Saw SM, Tan D. Pterygium: prevalence, demography and risk factors. Ophthalmic Epidemiol 1999; 6: 219-228.

7 Threlfall TJ, English DR. Sun exposure and pterygium of the eye: a dose-response curve. Am J Ophthalmol 1999; 128: 280-287.

8 Mathur ML, Haldiya KR, Sachdev R, Saiyed HN. The risk of pterygium in salt workers. Int Ophthalmol 2005; 26: 43-47.

9 McCarty CA, Tu CL, Taylor HR. Epidemiology of pterygium in Victoria, Australia. Br J Ophthalmol 2000; 84: 289-292.

$10 \mathrm{Wu} \mathrm{K}, \mathrm{He} \mathrm{M}, \mathrm{Xu} \mathrm{J}$, Li S. Pterygium in aged population in Doumen County, China. Yan Ke Xue Bao 2002; 18: 181-184

11 World Health Organization. Methods of Assessment of Avoidable Blindness. World Health Organization: Geneva, 1980.

12 Bandeen-Roche K, Munoz B, Tielsch JM, West SK, Schein OD. Self-reported assessment of dry eye in a populationbased setting. Invest Ophthalmol Vis Sci 1997; 38: 2469-2475.

13 Taylor HR, West SK, Rosenthal FS, Munoz B, Newland HS, Ernrnett EA. Corneal changes associated with chronic UV irradiation. Arch Ophthalmol 1989; 107: 1481-1484.

14 Tan DTH, Chee SP, Dear KB, Lim AS. Effect of pterygium morphology on pterygium recurrence in a controlled trial comparing conjunctival autografting with bare sclera excision. Arch Ophthalmol 1997; 115: 1235-1240.

15 Wong TY, Foster PJ, Johnson GJ, Seah SK, Tan DTH. The prevalence and risk factors for pterygium in an adult Chinese population in Singapore: the Tanjong Pagar Survey. Am J Ophthalmol 2001; 131: 176-183.

16 Chylack Jr LT, Wolfe JK, Singer DM, Leske MC, Bullimore MA, Bailey IL et al. The lens opacities classification system III. The Longitudinal Study of Cataract Study Group. Arch Ophthalmol 1993; 111: 831-836.

17 Karbassi M, Khu PM, Singer DM, Chylack Jr LT. Evaluation of lens opacities classification system III applied at the slitlamp. Optom Vision Sci 1993; 70: 923-928.

18 Dunzhu S, Wang FS, Courtright P, Liu L, Tenzing C, Noertjojo $\mathrm{K}$ et al. Blindness and eye diseases in Tibet: findings from a randomised, population based survey. $\mathrm{Br} J$ Ophthalmol 2003; 87: 1443-1448.

19 Kerkenczov N. A pterygium survey of the far northcoast of New South Wales. Trans Ophthalmol Soc Aust 1956; 16: 110-119.

20 Liu H, Yang J, Zhong L. Prevalence survey on pterygium in two counties of Hainan Province. Zhounhua Yan Ke Za Zhi 2001; 37: 21-23.

21 Panchapakesan J, Hourihan F, Mitchell P. Prevalence of pterygium and pinguecula: the Blue Mountains Eye study. Aust N Z J Ophthalmol 1998; 26(Suppl): S2-S5.

22 Tan CS, Lim TH, Koh WP, Liew GC, Hoh ST, Tan CC et al. Epidemiology of pterygium on a tropical island in the Riau Archipelage. Eye 2006; 20: 908-912.

23 Luthra R, Menesure BB, Wu SY, Xie SH, Leske C. Barbados Eye Studies Group. Frequency and risk factors for pterygium in the Barbados Eye Study. Arch Ophthalmol 2001; 119: $1827-1832$.

24 Butler FK, Harris DJ, Reynolds RD. Altitude retinopathy on Mount Everest, 1989. Ophthalmology 1992; 99: 739-746.

25 Wiedman M, Tabin GC. High-altitude retinopathy and altitude illness. Ophthalmology 1999; 106: 1924-1926.

26 Moran DJ, Hollows FC. Pterygium and ultraviolet radiation: a positive correlation. Br J Ophthalmol 1984; 68: 343-346. 
27 Mackenzie FD, Hirst LW, Battistuta D, Green A. Risk analysis in the development of pterygia. Ophthalmology 1992; 99: 1056-1061.

28 Forsius H, maertens K, Fellman J. Changes of the eye caused by the climate in Rwanda, Africa. Ophthalmic Epidemiol 1995; 2: 107-113

29 Rojas JR, Malaga H. Pterygium in Lima, Peru. Ann Opthalmol 1986; 18: 147-149.

30 Rosenthal FS, Bakalian AE, Lou C, Taylor HR. The effect of sunglasses on ocular exposure to ultraviolet radiation. Am J Publ Health 1988; 78: 72-74.
31 Lee AJ, Lee J, Saw SM, Gazzard G, Koh D, Widjaja D et al. Prevalence and risk factors associated with dry eye symptoms: a population based study in Indonesia. Br J Ophthalmol 2002; 86: 1347-1351.

32 Ishioka M, Shimmura S, Yagi Y, Tsubota K. Pterygium and dry eye. Ophthalmologica 2001; 215: 209-211.

33 Khoo J, Saw SM, Danerjee K, Shia SE, Tan D. Outdoor work and the risk of pterygia: a case control study. Int Ophthalmol 1998; 22: 293-298. 